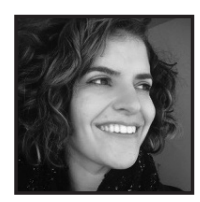

\title{
Artful Research Approaches in \#amwritingwithbaby: Qualitative Analysis of Academic Mothers on Facebook ${ }^{1}$
}

\author{
A. S. CohenMiller, Nazarbayev University
}

\begin{abstract}
This study contemplates one facet of academic motherhood through the use of artful research approaches in qualitative research to examine the (im)balance of being a mother writing academic works while raising and caring for a young child, as presented in an online hashtag Facebook campaign, \#amwritingwithbaby. Specifically, this study uses an analysis of online posts and arts-based representations of findings through a comparison of narrative, poem, and word clouds. Through using popular media for representing the findings, this study helps address the accessibility of artful inquiry into the growing body of works seeking equity for women and mothers in academia.
\end{abstract}

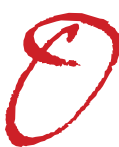

n March 22, 2015, Karen Kelsky, a former tenured professor who moved out of the professoriate and into a highly popular academic coach, requested her followers on Facebook to post a photo demonstrating how it is possible to complete academic work while raising and caring for a young child. Kelsky's (2016) followers at The Professor Is In, and the associated Facebook group, were asked to simply, "Hey, please share your photos of writing with babies! Call it \#amwritingwithbaby! Let's show it can be done!" Shortly after posting, there were over 150 likes, comments, and shares on the hashtag she suggested, \#amwritingwithbaby. Women (along with a handful of images including men and a few including pets) posted photos demonstrating the combination of working and taking care of young children/babies. Most of the photos also included a brief description explaining what the mother and baby were completing at the time, such as finishing a dissertation 
chapter or revising and resubmitting a manuscript. In some instances, there was a brief history provided giving context, such as by explaining soon after a picture was taken, the mother reached tenure.

Many of the comments on the photos were supportive and demonstrated how women felt empowered by seeing and hearing about the experiences of other mothers in academia. However, there was a select set of comments that started the discussion, mentioning a varied perspective. Those first sets of comments deviated from the latter ones by not including a photo and positive caption about completing academic work, but instead detailed conflicted feelings related to the campaign itself. The complexity of women's lives as mothers and scholars was highlighted, pointing to the duality of feeling empowered and sad/bothered by the need for mothers to balance both home and academic work. In other words, mothers' need to balance both home and academic work in this campaign pointed to larger issues about work/life policies, gender in academia, mothers in academia, the glass ceiling for women in the workplace, and the academic pipeline in general.

These comments posted about troublesome sociocultural policies and practices relating to academic mothers, at times referred to as "mother-scholars" (Lapayese, 2012) or motherscholars² (Matias, 2011), shed light on persistent problems in general inhibiting recruitment, retention, and equity in academia. Representations indicate inequality between those graduating and those moving throughout the academic pipeline that is a matter of concern for providing equity in academia (CohenMiller, 2014b). Institutions of higher education, primarily established to develop men, have transitioned over the years to accept women, yet despite allowing women in the classrooms and as faculty, there are still gaps in enrolment and positions (Mason, Wolfinger, \& Goulden, 2013). Additionally, the faculties of assistant, associate, and full professors in the United States and in Canada have shown significantly disproportionate representation of women (American Association of University Professors, 2014; Canadian Association of University Teachers, 2015). While we have seen an increase of women in higher education in Western nations, even outnumbering men in some graduate programs (Allum \& Okahana, 2015), there are obstacles faced by women internationally (Women in academia, 2015) and continued problems regarding promotion of female academics to full professor (Misra, Lundquist, Holmes, \& Agiomavritis, 2011).

Previous research has shown a preliminary understanding of the challenges faced by mothers in academia, as seen through online texts (CohenMiller, 2013). Furthermore, additional research explains there is a glass ceiling hindering women from reaching the highest levels of the professoriate (Williams, 2005). In other cases, 
it is argued there is another obstacle that stands in women's ways of progressing through the academic pipeline, the maternal wall. According to Williams and Segal (2003), the "maternal wall" is an obstacle that emerges once women are associated with family, whether becoming pregnant or having a child. Thus, to be associated with family life becomes negatively linked for women in academia. In contrast to the negative association for women in academia, for men, research indicates family does not hinder productivity or perceptions from others, but instead enhances their academic output, "Women who have children soon after receiving their Ph.D. are much less likely to achieve tenure than men who have children at the same point in their career" (Williams, 2005, p. 91). In other words, women in academia, often already underrepresented in faculty positions, especially at the most senior levels, are penalized within their academic career for becoming mothers and being associated with the family. While this is not unique to academia, it is a key element to address in working to reduce/eliminate discrimination and establishing equity in higher education, such as in recruitment and retention of women throughout the academic pipeline.

Continued efforts persist to thwart discrimination against women in academia, in particular as it relates to pregnancy (Mason \& Younger, 2014) and can be seen in the movement towards bringing together the identities of mother and academic as an act of resistance (Matias, 2011) to traditional practices in the academe. These efforts to improve equity in academia for academic mothers can be seen in an additional way through national funding, such as in the United States with Title IX regulations and with National Science Foundation (NSF) funding. Enforcing regulations around Title IX, which were established to equalize women's access to higher education and prevent discrimination, has not been without issues. Yet some of these challenges are being addressed. For instance, NSF funding, which provides considerable financial support for research, has recently challenged discriminatory behavior, pointing out, "The National Science Foundation (NSF) joins with other leading U.S. scientific organizations to emphasize its strong commitment to preventing harassment and to eradicate genderbased discrimination in science" (Press release, 2016, para. 1). Ultimately, the public discourse and academic research points to a continued need to address obstacles hindering the success and equity of women, and mothers, in academia.

\section{An Artful Research Approach}

This study contemplates one facet of academic motherhood (see Adrienne Rich, 1976/1995, for discussion on the "institution" of motherhood) in terms of the (im)balance of being a mother writing academic works while raising and caring for 
a young child. Through the use of an artful research approach-and arts-based practices - in qualitative research, this study examines the online hashtag Facebook campaign, \#amwritingwithbaby. Specifically, this study uses an analysis of online posts and presents the findings through arts-based representations-narrative, poem, and word clouds. It is hoped this study can expand upon our understanding of motherhood in academia and the ways in which findings can be represented for a greater comprehension of the topic. Through using popular media and arts-based representations, this study helps enhance the accessibility of works seeking equity for women and mothers in academia.

\section{Artful Research Design: Methods, Analysis, and Findings}

For this study, the purpose was to examine one facet of academic motherhood, the (im)balance of being a mother writing academic works while raising and caring for a young child, as presented in an online hashtag Facebook campaign, \#amwritingwithbaby. While not initially intending to utilize an artful research design, once I began working with the data, I quickly saw the need to delve within the qualitative research paradigm, specifically into arts-based research practices, in order to more fully understand, show, and describe the comments posted by the academic mothers. Additionally, I brought my work to colleagues to assess the degree to which I accomplished (re)presenting the narratives as is common with artsbased practices which address sensitive topics (Leavy, 2009). For this artful research design, I describe the thought processes and detail the applications of data collection, analysis, and findings.

To collect the data, I started with the original post on Karen Kelsky's Facebook page, The Professor Is In, as a stepping-off point. I downloaded all associated images, comments related to the images, and comments (posts) that did not include an image. Her post stated "Hey, please share your photos of writing with babies! Call it \#amwritingwithbaby! Let's show it can be done!" (Facebook post, March 22, 2015). The response on Facebook included 155 likes, 67 comments, and 27 shares. (Interestingly, Kelsky also posted on Twitter and had surprisingly different responses, with one person uploading an image of her dog and one person re-sharing.)

After downloading all comments/responses to Kelsky's post $(n=67)$, each verbal response was saved within a Word document. Images were saved separately along with the associated caption(s). While the images were not used as research tools for analysis of the text, they provided context for understanding and interpreting the comments. For instance, one photo included a comment, "good thing my arms are long." Without the associated image (see Figure 1), there is no context to understand 
the meaning of the words. In examining the image, a photograph showing a protruding, apparently pregnant woman's stomach extending towards a desk, it becomes clear the academic mother is referring to the utility of her arms ("good thing my arms are long") to get beyond her pregnant belly to reach the laptop computer.

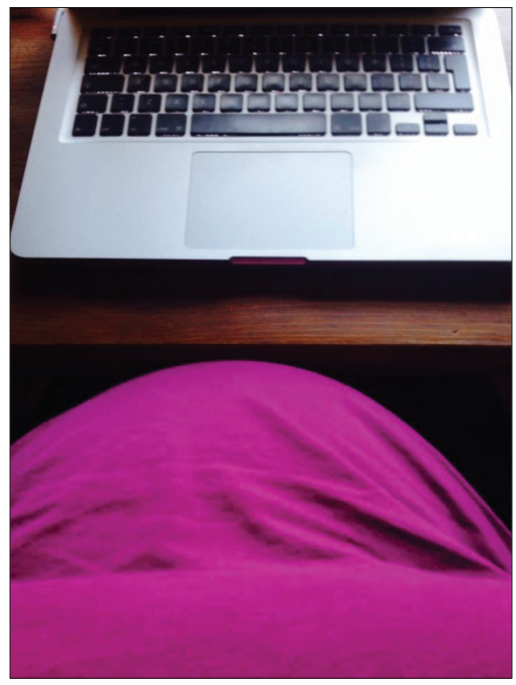

Fig. 1: An academic mother's vantage of having to reach across her pregnant belly to reach her computer

In compiling all the comments into one document, the total number of words from the comments reached just over 1,400. When I began the analysis, I had planned to go through the text line by line, coding for key words, concepts, and themes. This method of constant analysis, gleaned from typical grounded theory methods (Glaser \& Strauss, 1967; Charmaz, 2006), began the processes of analysis. Yet after beginning this process and working through multiple lines of text, I realized there was something different calling from the data, something asking to be revealed as a comprehensive unit instead of broken apart line by line. Allowing the data to speak is not a simple task, as there are typical methods of analysis, which generally dictate the manner of analysis and representation.

However, knowing there are times when data can urge depth of meaning through representations such as artful approaches, I switched gears and instead looked into the full text. I worked to let go of learned ways of data analysis and instead embrace more emergent methods addressing the digital data (Hesse-Biber \& Leavy, 2006; Markham, in press). What did the full set of 1,400 words say? What was being presented by the various mothers in academia? What was the overall feeling from this data and from those contributing their thoughts and experiences? 
When the captions were added together into one cohesive unit, I found they presented a narrative of the (im)balance of being a mother writing academic works while raising and caring for a young child. While the words provide many insights into the experiences of those posting \#amwritingwithbaby, as mentioned previously, the words did not provide the whole picture. For instance, one academic mother's comment, "I was even fortunate enough to have a research assistant," appears to present a positive feeling of having support, yet the image that accompanied the quote shows a different aspect. The image (see Figure 2) showed a young baby crawling towards a set of academic books. As the image focuses on the baby, without situating the academic mother in the picture, it appears the baby is the only one with access to the books (as toys?) and thus suggests the difficulty of completing academic work.

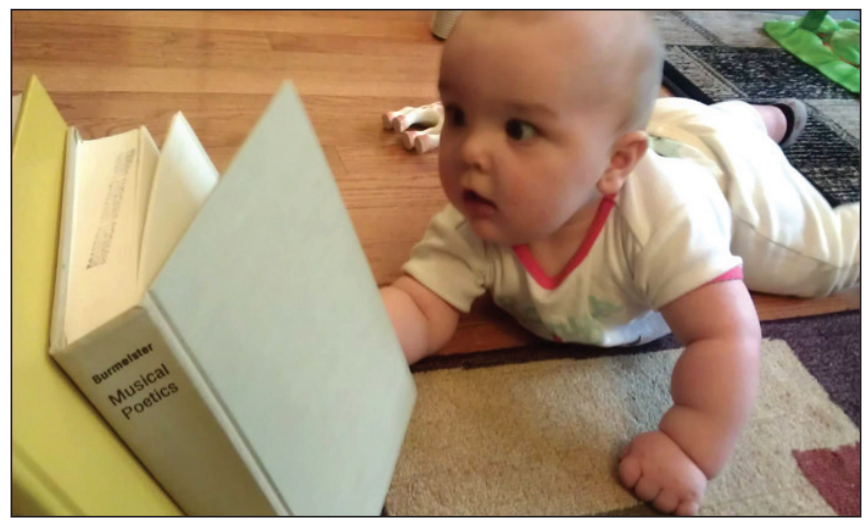

Fig. 2: Baby crawling towards and touching academic books

Moving forward with the analysis, I found that collecting the comments into one narrative presented a particular vantage into the overall synthesis and feeling of the data. As an example, I have selected one portion of the comments, all of which were posted consecutively on the Facebook post.

Finished data collection on my last study participant while I was in labor. I love this thread! Dissertating with baby. When my son was 1 month old I did the final proofs for my monograph while nursing on one side and pumping on the other side. So many days I nursed my daughter to sleep and she rested beside me as I typed. Because it was what we had, we were on a sofa, my laptop sat perched on a TV tray in front of me. She was born in June, this was taken in Nov[ember], and I graduated in Dec[ember]. More lab work. (Looking through specimens). An office work day, visiting colleagues for manuscript work. I was even fortunate enough to have a research assistant. I shared this on another comment, but here it is again. National conference paper, son about 
2 months old here. This is my first [baby], when I was working on a book proposal. I'm now writing my manuscript while holding my second [baby]. Helping me sort journal articles. Nursing and outlining a book chapter right now!

The comments present a narrative of beginning research, writing, and completing various assignments. These comments are collected from multiple academic mothers, with one comment addressing the availability of work space-the sofa and TV trayconjuring imagery of a small space that was used for academic work. Below (see Table 1) I separate each line based upon each person who made a comment on the Facebook thread.

\section{Table 1}

\section{Selected set of comments separated by individual academic mother who posted on} the Facebook thread \#amwriting withbaby

1 Finished data collection on my last study participant while I was in labor.

2 Ilove this thread!

3 Dissertating with baby.

4 When my son was 1 month old I did the final proofs for my monograph while nursing on one side and pumping on the other side.

5 So many days I nursed my daughter to sleep and she rested beside me as I typed. Because it was what we had, we were on a sofa, my laptop sat perched on a TV tray in front of me.

6 She was born in June, this was taken in Nov[ember], and I graduated in Dec[ember].

7 More lab work. (Looking through specimens).

8 An office work day, visiting colleagues for manuscript work.

9 I was even fortunate enough to have a research assistant. I shared this on another comment, but here it is again.

10 National conference paper, son about 2 months old here.

11 This is my first [baby], when I was working on a book proposal.

12 I'm now writing my manuscript while holding my second [baby].

13 Helping me sort journal articles.

14 Nursing and outlining a book chapter right now! 
In addition to hearing the narrative of the mothers and incorporating the images they included, I also felt drawn by the data to present the comments in additional artful modalities. In creating an additional mode of representation, there is potential for further understanding by audiences who may not all be drawn to the same representation. I chose to present the data in two additional formats: as a poem and as word clouds.

For the development of the poem, I used the same comments included above within the narrative and in the table, spaced and commented upon. In taking this step, I found the words provided expanded meaning. I used the selection of the comments as presented in the narrative, but have turned them into a poem, adding my own thoughts, in brackets, to move the poem along. The other intention of the bracketed words is to provide the reader with the potential feelings behind the academic mother comments (and associated images). In other words, deep analysis of the content and connotation of the words was being conducted through the development of a poem.

\author{
Finished \\ data collection on my last study participant \\ while I was in labor. \\ [Breathing. Sighing] \\ Dissertating \\ with baby. \\ [We are almost done. We are almost there.] \\ When my son was 1 month \\ I did the final proofs \\ for my monograph while nursing \\ on one side and pumping on the other side. \\ [Did you hear? Not 1 year old. Not a full 12 months. \\ Barely out of the womb. 30 days, 1 month]
}

So many days I nursed my daughter to sleep and she rested beside me as I typed.

Because it was what we had,

we were on an [sic] sofa,

my laptop sat perched on a TV tray in front of me.

[You see, we can do it all.

Is that our goal?

Have we reached it yet?] 
Lastly, the same set of comments were further analyzed through the technique of developing a word cloud. A "word cloud" is a digital tool to visually represent the most utilized words within a section of text. The words that are presented in a larger font are the ones that are more frequently used. Similarly, the words in smaller text size have been used less frequently in the selection of text. In other words, a word cloud is a quick way to see the gist of a set of text. Like a bar graph can provide an overview of a set of data, the word cloud provides an overview of a set of data in the form of words. With this in mind, the last step of the analysis included creating multiple sets of word clouds.

Through the use of an online tool, text can be entered and a word cloud is presented (see Wordle.net or http://www.abcya.com/word_clouds.htm). There are various ways in which the preferences in representation can be tweaked such as by color family, orientation of words, and size. While it is a fairly straightforward technique for analysis, there are times, such as in this case, it was important to go through the text and correct/update words for comprehensibility. The first word cloud presented below (see Figure 3) utilizes the same set of words from the 13 academic mothers who posted, which were used for the narrative and a selection was used for the poem. The most common words were: baby and work. Additional words that were commonly used included: book, manuscript, old, son, nursing, and side.

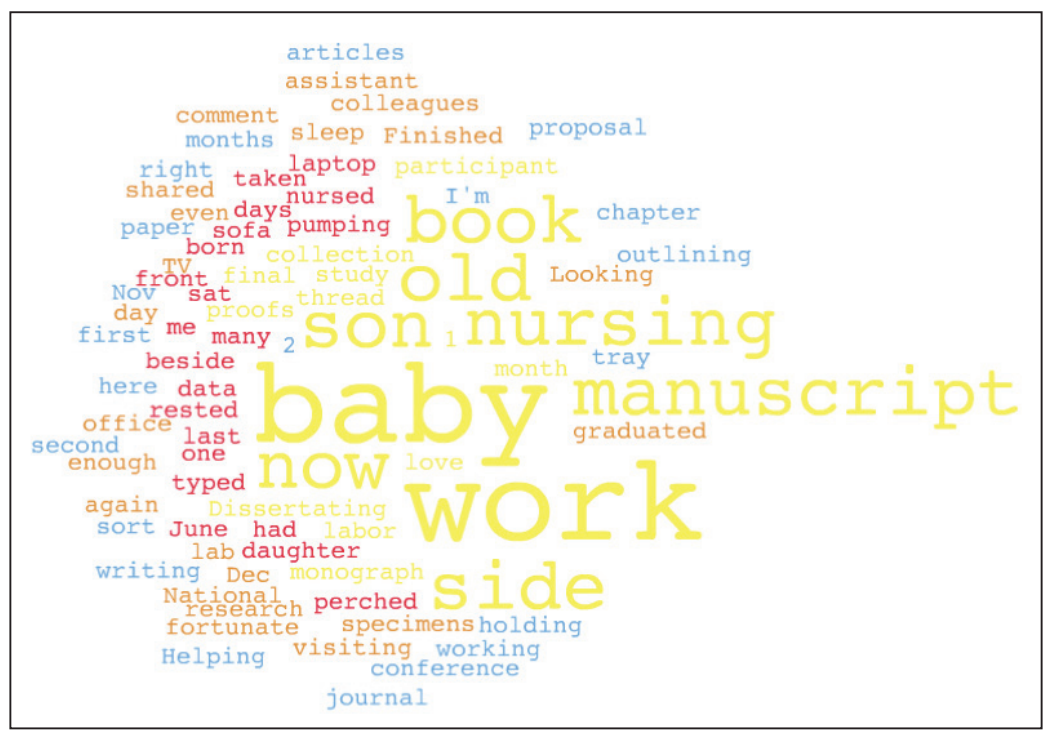

Fig. 3: Word cloud using the selected set of 13 comments from the narrative 
In order to get a fuller picture of the overall feeling of the totality of comments and understandings of the academic mothers' posts on \#amworkingwithbaby, I created three additional word clouds. The first additional word cloud included a set of eight comments discussing a conflict of feelings and concern about the "social pressure of being a supermom" (see Figure 4). The most common words were: time, during, and yes. Additional common words used included: academia, babies, academic, photos, expectations, expected, recovery, hand, sad, quite, support, women, many, leave, post, thank, second, done, maternity, and writing.

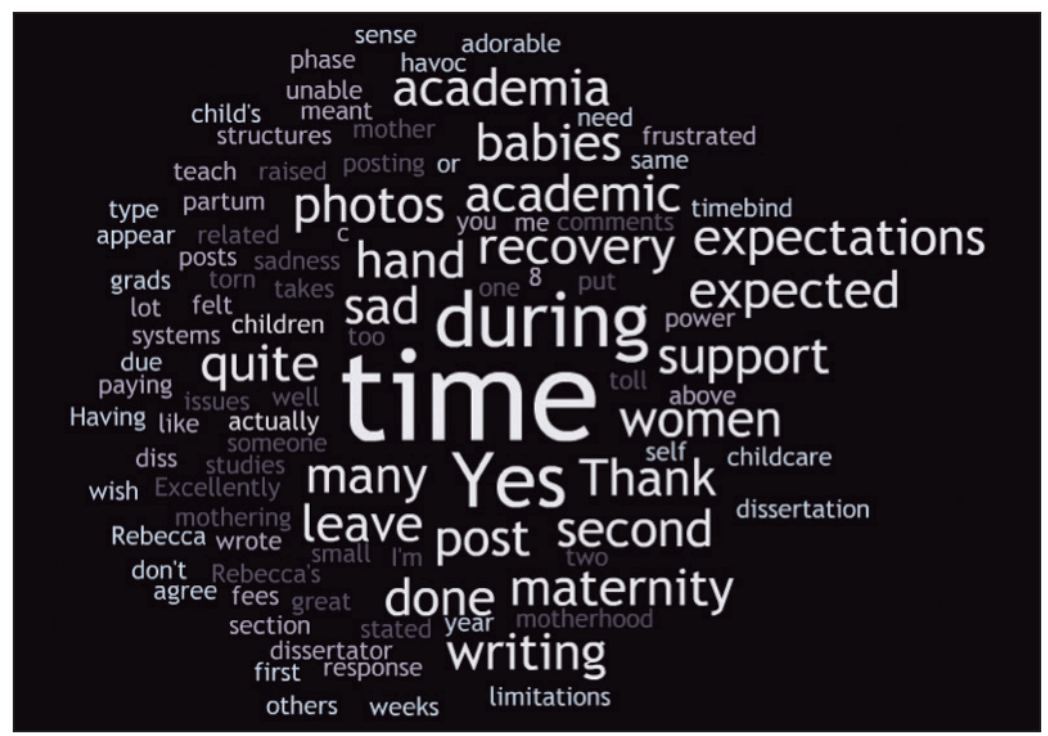

Fig. 4: Word cloud using a set of eight comments discussing a conflict of feeling

The next word cloud included the remaining 59 comments and excluded the first set of nine comments (see Figure 5). The most common words were: one, writing, dissertation, working, and baby. Additional common words used included: book, chapter, daughter, home, tenure, manuscript, I'm, first, son, write, work, defended, paper, amwritingwithbaby, helping, and conference. 


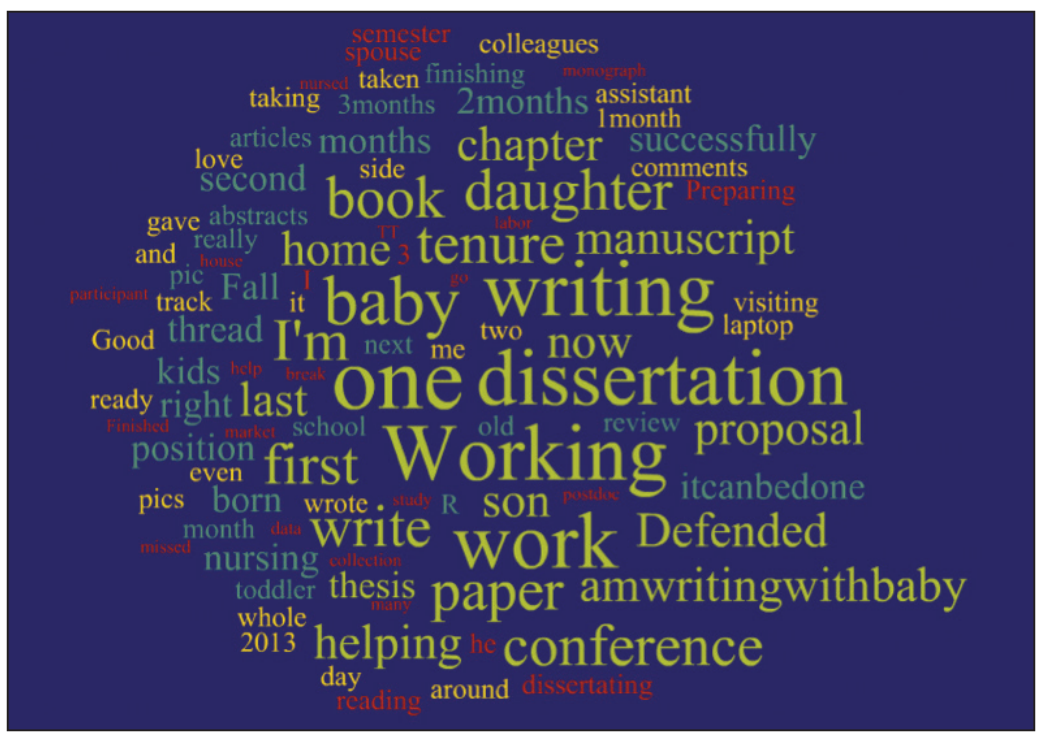

Fig. 5: Word cloud using a set of 59 comments, excluding the first set of nine comments discussing a conflict of feelings

Lastly, the final word cloud included all comments from the post \#amworkingwithbaby (see Figure 6). The most common words are: baby, one, writing, dissertation, and working. Additional common words used included: amwritingwithbaby, daughter, proposal, paper, home, write, I'm, book, last, tenure, son, first, second, time, now, helping, conference, and defended.

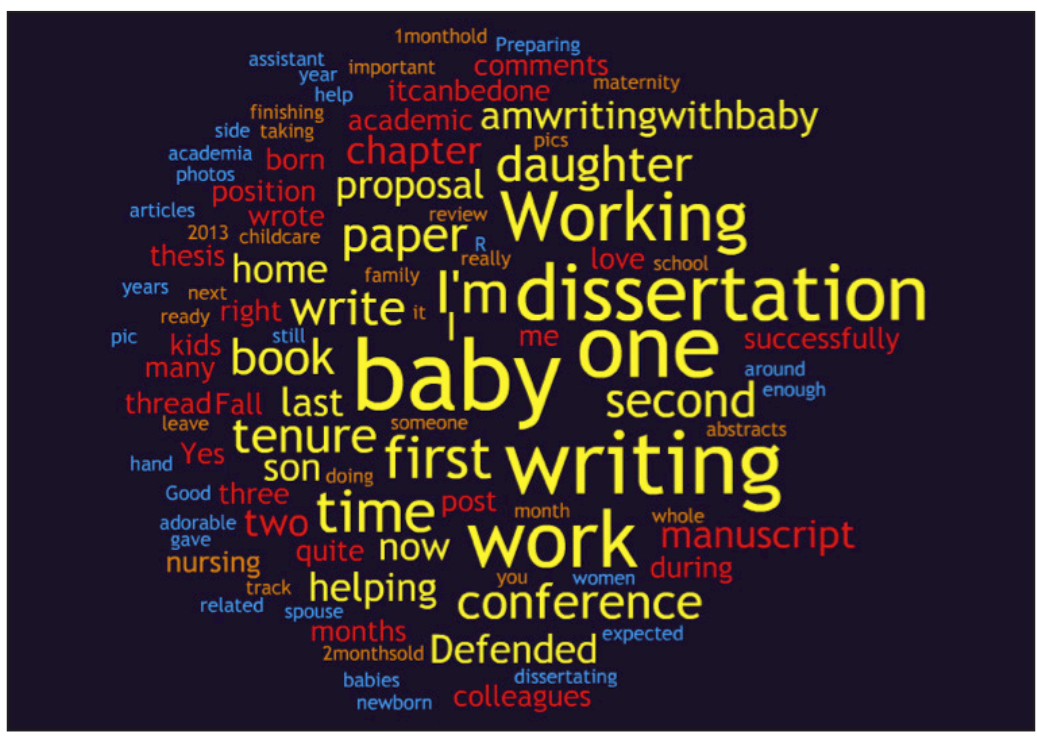

Fig. 6: Word cloud using all comments from the Facebook post, \#amworkingwithbaby 
These four word clouds, while providing similar sets of words that are used most frequently, ultimately end up highlighting a slightly different perspective on the experiences of \#amwritingwithbaby. Likewise, the narrative and poem each present a nuanced perspective into the (im)balance of academic mothers' work. Across the four word clouds, the academic mothers' experiences can be seen through common types of terminology relating to writing (e.g., book, manuscript), feelings (e.g., expectations, sad), and children (e.g., daughter, son, first [child]). (See Table 2.)

Table 2

Commonly discussed words relating to writing and feelings. Organized by word cloud

\begin{tabular}{|c|c|c|c|c|}
\hline & WORD CLOUD 1 & WORD CLOUD 2 & WORD CLOUD 3 & WORD CLOUD 4 \\
\hline Writing & $\begin{array}{l}\text { Manuscript } \\
\text { Dissertation } \\
\text { Chapter } \\
\text { Proposal } \\
\text { Book } \\
\text { Conference }\end{array}$ & $\begin{array}{l}\text { Writing } \\
\text { Dissertation }\end{array}$ & $\begin{array}{l}\text { Writing } \\
\text { Chapter } \\
\text { Manuscript } \\
\text { Dissertation } \\
\text { Proposal } \\
\text { Review } \\
\text { Paper } \\
\text { Thesis } \\
\text { Conference }\end{array}$ & $\begin{array}{l}\text { Dissertation } \\
\text { Working } \\
\text { Writing } \\
\text { Manuscript } \\
\text { Proposal } \\
\text { Chapter } \\
\text { Conference }\end{array}$ \\
\hline Feelings & $\begin{array}{l}\text { Enough } \\
\text { Love } \\
\text { Now }\end{array}$ & $\begin{array}{l}\text { Time bind } \\
\text { Frustrated } \\
\text { Support } \\
\text { Thank } \\
\text { Leave } \\
\text { Sadness } \\
\text { Limitations } \\
\text { Expectations } \\
\text { Expected } \\
\text { Power } \\
\text { Havoc } \\
\text { Adorable }\end{array}$ & $\begin{array}{l}\text { Successfully } \\
\text { Preparing } \\
\text { \#itcanbedone } \\
\text { Helping } \\
\text { Good }\end{array}$ & $\begin{array}{l}\text { \#itcanbedone } \\
\text { Successfully } \\
\text { Enough } \\
\text { Expected }\end{array}$ \\
\hline
\end{tabular}


Across the data, we can see academic mothers provide contextualization for the types of writing they are engaged with, while caring for and raising young children. These types of writings include writing "in general" and writing chapters, manuscripts, dissertations/theses, proposals, review, papers, and conference articles. Throughout the discussion of the types of writing these women engage with in academia, they also present embedded concepts relating to their feeling of (im)balance in being a mother writing academic works while raising and caring for a young child. Such emotional contexts are provided through words including: enough, love, now, time bind, frustrated, support, thank, leave, sadness, limitations, expectations/expected, power, havoc, and adorable.

\section{Discussion}

The purpose of this study was to contemplate one facet of academic motherhood through the use of an artful research approach in qualitative research to examine the (im)balance of being a mother writing academic works while raising and caring for a young child. Specifically, the study presented data and analysis from the online hashtag campaign on Facebook from Karen Kelsky's page, The Professor Is In, where she requested comments and posting of images with the tag \#amwritingwithbaby. This study utilized multiple artful approaches in decoding the data as presented within the Facebook thread \#amwritingwithbaby. Through the use of artful data analysis-arts-based research practice-and presentations of findings including narrative, poem, and word clouds, the 67 comments from academic mothers provide a contextualization for the (im)balance of being a mother writing academic works while raising and caring for a young child.

Overall, there appears to be a complex relationship regarding the (im)balance of family and work for academic mothers, with opposing forces of stress/sadness and support/love. Such tension between feelings and experiences as seen in \#amworkingwithbaby can be found in previous research studying academic mothers, in particular highlighted in research studying graduate student motherhood in academia (CohenMiller, 2014b; Holm, Prosek, \& Godwin Weisberger, 2015; Tiu Wu, 2013; Trepal, Stinchfield, \& Haiyasoso, 2014). Findings suggest basic steps that can be implemented to support academic mothers, such as by providing accessible onsite childcare (CohenMiller, 2014a, 2014b), transparent policies, and a "culture" of using such policies (Ward \& Wolf-Wendel, 2012; Lundquist \& Misra, 2015). 
This study provides a first step in understanding how mothers in academia present themselves online within a Facebook hashtag campaign. While this study focuses on the comments posted, future research could delve first into the associated imagery of academic mothers (46 photographs) posted as part of \#amwritingwithbaby hashtag campaign. Furthermore, to provide deeper understanding of the (im)balance of being a mother writing academic works while raising and caring for a young child, an enhanced step to truly understand the experiences of these women would be to conduct interviews with them (e.g., a researcher could apply for permissions to approach the women who posted on Facebook). In this regard, interviews could be conducted as follow-up to the images and comments posted, as well as the presented analyses and findings. In other words, the academic mothers would have an opportunity to provide additional interpretation/explanation upon their comments, providing a more complete picture of their experiences. Future suggested research could relate to (1) how academic mothers feel regarding working alongside/with their young children,

(2) what types of supports (or lack thereof) are experienced/desired, and (3) what types of formal/informal learning developed as a result of being an academic mother. As we go forward delving deeper into the experiences of mothers in academia, there is hope for supporting recruitment, retention, and equity for women in academia through additional theoretical approaches, practices research, and methods.

\section{Notes}

1. An earlier version of this article was presented at the Southwest Popular and American Culture Association Conference (SWPACA), February 2016, in Albuquerque, New Mexico, USA. Conference travel was generously supported in part by a Social Policy grant from the Graduate School of Education at Nazarbayev University, Astana, Kazakhstan.

2. The term motherscholar (Matias, 2011) provides a way to "coalesce" the identities of being an academic and a mother. For this article, without speaking with the individual women about their preference for identifying themselves, I have selected the term "academic mother" to address the general concept of mothers working/ studying in academia. 


\section{References}

\#amwritingwithbaby. (2015). The professor is in. Retrieved from https://www.facebook.com/ hashtag/amwritingwithbaby? source=feed_ text\&story_id=893010550745493

Allum, J., \& Okahana, H. (2015). Graduate enrollment and degrees: 2004 to 2014. Washington, DC: Council of Graduate Schools.

American Association of University Professors. (2014). Table 5: Average Salary for Men and Women Faculty, by Category, Affiliation, and Academic Rank, 2013-14, 2013-14. Annual Report on the Economic Status of the Profession.

Canadian Association of University Teachers. (2015). Table 2.12: Average Salaries of Full-time. Permanent Women University Professors, College and Other Vocational Instructors, and All Occupations, 2014-2015 CAUT Almanac of Post-Secondary Education in Canada

Charmaz, K. (2006). Constructing grounded theory: A practical guide through qualitative analysis. London: Sage Publications.

CohenMiller, A. S. (2013). Motherhood in academia: A grounded theory pilot study of online texts. Northern Rocky Educational Researcher Association - The Researcher, 25(1), 47-66. http://www.nrmera.org/PDF/ Researcher/Researcherv25n1CohenMiller. pdf

CohenMiller, A. S. (2014a). Making doctoral student motherhood/mothering visible: Practical approaches for overcoming obstacles in academia. Museum of Motherhood Conference, New York.

CohenMiller, A. S. (2014b). The phenomenon of doctoral student motherhood/mothering in academia: Cultural construction, presentation of self, and situated learning. (PhD Dissertation), University of Texas at San Antonio, San Antonio, TX. ProQuest Dissertations \& Theses Full Text database.

Glaser, B. G., \& Strauss, A. (1967). The discovery of grounded theory: Strategies for qualitative research. Chicago: Aldine Publishing Company.
Hesse-Biber, S. N., \& Leavy, P. (Eds.). (2006). Emergent methods in social research. London: Sage Publications.

Holm, J. M., Prosek, E. A., \& Godwin Weisberger, A. C. (2015). A phenomenological investigation of counseling doctoral students becoming mothers. Counselor Education \& Supervision, 54, 1-16.

Kelsky, K. (2016). The professor is in. Retrieved from http://theprofessorisin.com

Lapayese, Y. V. (2012). Mother-scholar: (Re) imagining K-12 education. Rotterdam, The Netherlands: Sense Publishers.

Leavy, P. (2009). Social research and the creative arts: An introduction. Method meets art: Arts-based research practice (pp. 1-24). New York: Guilford Press.

Lundquist, J. H., \& Misra, J. (2015). The clogged pipeline. Inside Higher Ed. Retrieved from https://www.insidehighered.com/ advice/2015/07/20/essay-calls-new-meta phor-clogged-pipeline-academic-workforce

Markham, A. N. (in press). Ethnography in the digital era: From fields to flows, descriptions to interventions. In Denzin, N., \& Lincoln, Y. (Eds.). The Sage Handbook of Qualitative Research, 5th Edition. London: Sage.

Mason, M. A., Wolfinger, N. H., \& Goulden, M. (2013). Do babies matter?: Gender and family in the Ivory Tower. New Brunswick, NJ: Rutgers University Press.

Mason, M. A., \& Younger, J. (2014). Title IX and Pregnancy Discrimination in Higher Education: The New Frontier. 38. N.Y.U. Rev. L. \& Soc. Change 269. Retrieved from http:// scholarship.law.berkeley.edu/facpubs/2470

Matias, C. (2011). "Cheryl Matias, PhD and Mother of Twins": Counter storytelling to critically analyze how I navigated the academic application, negotiation, and relocation process. Division G - Social Context of Education / Section 2. Paper presented at the American Educational Research Association (AERA), New Orleans, LA. 
Misra, J., Lundquist, J. H., Holmes, E., \& Agiomavritis, S. (2011). The ivory ceiling of service work. Academe. Retrieved from http://www.aaup.org/article/ivory-ceilingservice-work\#.VqmH5rTUVFI

Rich, A. (1976/1995). Of woman born: Motherhood as experience and institution. New York: W. W. Norton \& Company, Inc.

The National Science Foundation. (2016, January 25). The National Science Foundation (NSF) will not tolerate harassment at grantee institutions. Press Release.

Tiu Wu, A. (2013). Learning to balance: Exploring how women doctoral students navigate school, motherhood and employment. (3556422 Ed.D.), Teachers College, Columbia University, New York. ProQuest Dissertations \& Theses Full Text database.

Trepal, H. C., Stinchfield, T. A., \& Haiyasoso, M. (2014). Great expectations: Doctoral student mothers in counselor education. Adultspan, 13(1), 30-45.
Ward, K., \& Wolf-Wendel, L. E. (2012). Academic motherhood: How faculty manage work and family. Chapel Hill, NC: Rutgers University Press.

Williams, J. C. (2005). The glass ceiling and the maternal wall in academia. New Directions for Higher Education, (130), 91-105.

Williams, J. C., \& Segal, N. (2003). Beyond the maternal wall: Relief for family caregivers who are discriminated against on the job. Harvard Women's Law Journal, 26, 77-162.

Women in academia. (2015). Report, Catalyst: Changing workplaces. Changing lives. Retrieved from http://www.catalyst.org/ knowledge/women-academia\#comment _response

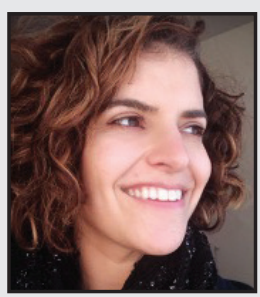

A. S. CohenMiller is an Assistant Professor in the Graduate School of Education at Nazarbayev University in Astana, Kazakhstan. Dr. CohenMiller's interests include exploring multimodal/arts-informed aspects of qualitative research, especially as it relates to the recruitment, retention, and equity for women in academia. She is also the Founding Co-Editor and Managing Editor of Dialogue: The Interdisciplinary Journal of Popular Culture and Pedagogy. 